\title{
PENDUGAAN STOK KARBON PADA POLA TANAM AGROFORESTRI SEDERHANA DAN AGROFORESTRI KOMPLEKS DI KPH BATUTEGI, KABUPATEN TANGGAMUS
}

\author{
Carbon Stock Estimation In Simple And Complex Agroforestry Cropping Patterns In \\ KPH Batutegi, Tanggamus Regency \\ Christine Wulandari ${ }^{\star}$, Sugeng P. Harianto, Destia Novasari \\ Program Studi Magister Kehutanan Jurusan Kehutanan, Universitas Lampung \\ Jl. Prof. Dr. Ir. Sumantri Brojonegoro No. 1, Bandar Lampung, Lampung \\ *Email: christine.wulandari@fp.unila.ac.id
}

Diterima: 08/10/2020, Direvisi: 28/10/2020, Disetujui: 08/11/2020

\begin{abstract}
Global warming is a natural phenomenon that is currently taking place. Natural phenomena occur as a result of changing ecosystem balance. This can be minimized by adding vegetation which acts as $\mathrm{CO}_{2}$ to convert $\mathrm{CO}_{2}$ into glucose and oxygen through the process of photosynthesis. Each type of vegetation has the potential to absorb different carbon, so this can be circumvented by using the right cropping pattern. Therefore, information about the potential for carbon stored in complex and simple agroforestry cropping patterns in KPH Batutegi is important. The purpose of this study was to analyze carbon stocks in agroforestry cropping patterns and to compare carbon stocks in simple and complex agroforestry cropping patterns in KPH Batutegi. Source of living tree biomass, dead tree biomass, understorey biomass, and litter biomass. The results showed that the carbon stored in complex agroforestry cropping patterns fell into the good category according to the Intergovermental Panel on Climate Change (IPCC). However, the stored carbon in complex agroforestry cropping patterns is greater than the stored carbon in simple agroforestry cropping patterns, namely 765.61 tonC/ha and 356.21 tonC/ha.
\end{abstract}

Keywords: Biomass; carbon stock; complex agroforestry; Simple agroforestry

\begin{abstract}
ABSTRAK
Pemanasan global merupakan fenomena alam yang sedang berlangsung saat ini. Fenomena alam terjadi akibat dari keseimbangan ekosistem yang berubah. Hal tersebut dapat diminimalisir dengan melakukan penambahan vegetasi yang berperan sebagai penyerap $\mathrm{CO}_{2}$ dan kemudian merubah $\mathrm{CO}_{2}$ menjadi glukosa dan oksigen melalui proses fotosintesis. Setiap jenis vegetasi memiliki potensi menyerap karbon berbeda-beda, sehingga hal tersebut dapat disiasati dengan melakukan penggunaan pola tanam yang tepat. Informasi mengenai potensi stok karbon pada pola tanam agroforestri sederhana dan kompleks di KPH Batutegi menjadi penting untuk dapat mengetahui potensi KPH ini dalam menjerap karbon sekaligus perannya dalam mengurangi emisi karbon. Penelitian ini mempunyai tujuan untuk menganalisis stok karbon pada tanam agroforestri dan
\end{abstract}


membandingkan cadangan karbon pada pola tanam agroforestri sederhana dengan agroforestri kompleks di KPH Batutegi. Analisis karbon berdasarkan analisis biomassa pohon hidup, biomassa pohon mati, biomassa tumbuhan bawah, dan biomassa serasah. Hasil penelitian menunjukan bahwa karbon tersimpan pada pola tanam agroforestri kompleks masuk kedalam kategori baik menurut Intergovermental Panel on Climate Change (IPCC). Diketahui bahwa kandungan karbon tersimpan pada pola tanam agroforestri kompleks lebih banyak dibandingkan dengan karbon tersimpan pada pola tanam agroforestri sederhana yaitu 765.61 ton/ha dan 356.21 ton/ha.

Kata kunci : Agroforesri Kompleks; agroforesri sederhana; biomassa; karbon tersimpan

\section{PENDAHULUAN}

Salah satu fenomena alam yang mengancam keberlangsungan hidup di bumi adalah kenaikan suhu bumi yang biasa disebut dengan pemanasan global (Riswakhyuningsih 2015). Pemanasan global terjadi karena adanya peningkatan gas-gas rumah kaca yang mengakibatkan terjadinya terjadi pemantulan energi panas bumi (Rizki et al. 2016). Salah satu penyebab kenaikan suhu bumi adalah sumberdaya dan lingkungan yang rusak akibat dari penggundulan dan pembakaran hutan, akibatnya adalah perubahan keseimbangan ekosistem (Arifin 2015; Bhaskara 2017; Partiwi 2019).

Penambahan vegetasi dapat menjadi solusi dalam meminimalisir perubahan suhu bumi. Hal ini sesuai hasil dari penelitian Dede et al. (2019) yang menyatakan bahwa penambahan vegetasi merupakan solusi terkait dengan permasalahan kenaikan suhu bumi. Vegetasi berperan sebagai penjerap gas karbondioksida $\left(\mathrm{CO}_{2}\right)$ dan merubahnya menjadi glukosa dan oksigen melalui bantuan sinar matahari dan air sehingga mengurangi peningkatan efek gas rumah kaca (Azham 2015; Rizki et al. 2016; Prihatmaji et al. 2016). Proses tersebut terjadi karena adanya proses fotosintesis pada vegetasi (Rizki et al. 2016). Kemampuan vegetasi dalam menyerap karbon berbeda-beda, sehingga hal tersebut dapat disiasati dengan mempertimbangkan jenis dan pola-pola tanam yang diaplikasikan pada suatu wilayah (Prihatmaji et al. 2016; Bhaskara 2017).

Pola tanam yang digunakan oleh sebagian besar petani penggarap lahan khususnya yang di lahan hutan negara adalah pola tanam agroforestri. Pola tanam agroforestrinya dengan menggunakan penggabungan jenis tanaman kehutanan dengan pertanian dan peternakan pada suatu lahan yang sama dengan tujuan untuk peningkatan hasil produksi tanaman (Wulandari et al. 2019; Alfatikha et al. 2020). Pola tanam agroforestri dibagi menjadi dua macam, yaitu pola tanam agroforestri kompleks dan agroforestri sederhana (Sukmawati et al. 2014). Agroforestri kompleks adalah teknik penggunaan lahan dengan menggunaan banyak jenis pohon yang tumbuh secara alami atau secara sengaja ditanam pada satu lahan sehingga dapat menyerupai hutan (Sumilia et al. 2019). Adapun yang disebut dengan agroforestri sederhana yaitu teknik pengelolaan hutan dengan cara menanam pepohonan secara tumpang sari dengan satu jenis tanaman semusim atau lebih dari satu (Fitri \& Ulfa 2015). Pemilihan tanaman kehutanan dilakukan berdasarkan berbagai faktor, salah satunya adalah faktor kesesuaian kondisi biofisiki lahan (Salampessy et al. 2017).

Kesatuan Pengelolan Hutan $(\mathrm{KPH})$ Batutegi merupakan salah satu unit pengelola hutan yang berada di Kabupaten Tanggamus, Provinsi Lampung. Salah satu pola tanam yang di terapkan di KPH Batutegi adalah agroforestri (Novasari 2019; Novasari et al. 2020). Berdasarkan hasil penelitian yang telah diimplementasikan oleh Aprianto et al. (2016), serapan 
karbon secara umum di KPH Batutegi masuk kedalam kategori baik. Penelitian-penelitian tentang potensi karbon tersebut belum membedakan pola agroforestri di lokasi penelitian. Polanya berupa agroforestri sederhana ataukah pola tanam agroforestri kompleks.

Pola tanam dengan kemampuan menyerap karbon yang baik dapat meminimalisir efek dari pemanasan global. Selain itu juga memberikan peluang dalam pejualan karbon dimasa mendatang (Stevanus \& Sahuri 2014) oleh karena itu, penelitian tentang stok karbon di KPH ini perlu dilakukan. Selain untuk dijadikan dasar dalam penyusunan rencana pengelolaan $\mathrm{KPH}$ Batutegi, juga untuk memperoleh sebutan sebagai masyarakat rendah karbon dan diharapkan akan memperoleh apresiasi sebagai bagian dari jasa lingkungan (Adinugroho et al. 2013). Selain itu, dengan diketahuinya besaran penyerapan karbon (pada setiap pola agroforestri) di lokasi penelitian, maka dapat dijadikan dasar analisis untuk mengetahui potensi pengurangan emisi karbon di KPH Batutegi (Yudha 2019). Penelitian ini bertujuan menganalisis stok karbon pada pola tanam agroforestri sederhana maupun kompleks di KPH Batutegi serta membandingkan cadangan karbon pada kedua pola tanam tersebut.

\section{METODE}

\section{Lokasi dan Waktu Penelitian}

Penelitian dilakukan pada bulan Agustus 2020 di Gabungan Kelompok Tani (Gapoktan) Sinar Harapan, KPH Batutegi, Kabupaten Tanggamus.

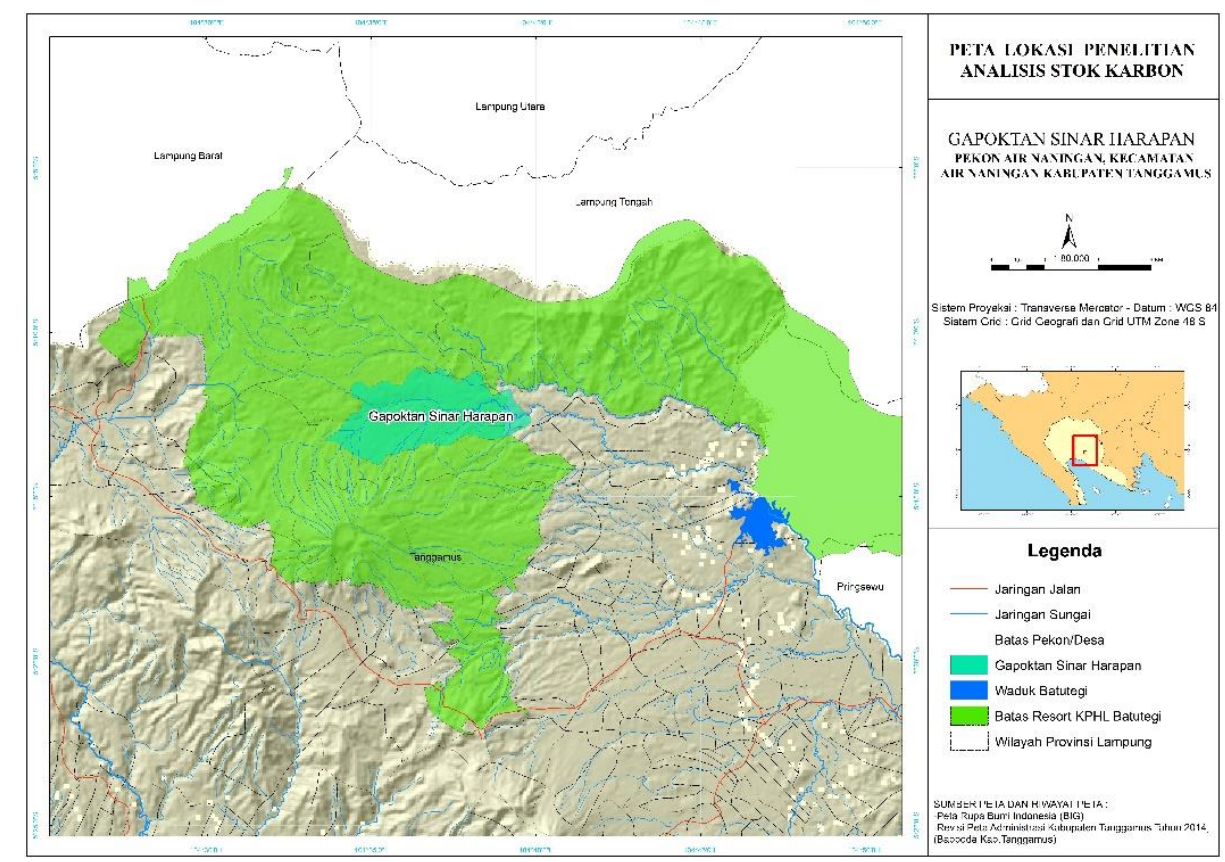

Gambar 1. Areal Gapoktan Sinar Harapan KPH Batutegi, Kabupaten Tanggamus

Figure 1. The area of the Sinar Harapan KPH Batutegi Gapoktan, Tanggamus Regency

\section{Pengambilan Data}

Data yang digunakan merupakan data primer. Pengambilan data dilakukan dengan menggunakan metode pemanenan (destruktif) untuk pengukuran biomassa nekromassa tak berkayu (serasah) dan tumbuhan bawah. Sedangkan pengukuran biomassa pohon hidup, dan 
pohon mati baik yang rebah maupun berdiri dilakukan dengan metode tanpa pemanenan (nondestruktif). Metode non destruktif dilakukan pada jenis pohon yang berukuran diameter $5 \mathrm{~cm}$ $>30 \mathrm{~cm}$ dan tanpa merusak pohonnya. Data yang diambil dengan cara ini berupa data diameter pohon berdiri dan tinggi pohon serta pencatatan nama jenis tanaman yang masuk kedalam plot ukur.

\section{Penentuan Plot Ukur}

Perhitungan cadangan karbon dilakukan dengan menggunakan Plot Ukur berbentuk persegi panjang dengan ukuran $100 \mathrm{~m} \times 20 \mathrm{~m}, 40 \mathrm{~m} \times 5 \mathrm{~m}$, dan 0,5m x 0,5m (Hairiah et al. 2011). Analisis Vegetas dilakuan dengan menggunakan plot ukur berbentuk persegi dengan ukuran $20 \mathrm{~m} \times 20 \mathrm{~m}, 10 \mathrm{~m} \times 10 \mathrm{~m}, 5 \mathrm{~m} \times 5 \mathrm{~m}, 2 \mathrm{~m} \times 2 \mathrm{~m}$. Penentuan plot ukur dilakukan dengan menggunakan metode purposive sampling baik pada pola tanam agroforestri kompleks maupun agroforestri sederhana (Aprianto 2015).

\section{Metode Analisis Data}

Analisis vegetasi dilakukan pada plot ukur kuadrat untuk melihat tingkat Indeks Nilai Penting (INP) serta Summed Dominance Ratio (SDR). Perhitungan SDR dilakukan setelah nilai INP didapatkan, untuk melihat jenis tanaman yang paling melimpah pada daerah penelitian (Indriyanto 2006). danPenentuan biomassa pohon pada pola tanam agroforestri kompleks dilakukan dengan menggunakan rumus allometrik yang dikemukanan oleh Hairiah dan Rahayu (2007) untuk jenis pohon hidup dan nekromassa bercabang. Sedangkan biomassa nekromassa tidak bercabang dilakukan dengan menggunakan rumus:

$$
\mathrm{BK}=\frac{\pi \mathrm{pH}}{40} \times D^{2}
$$

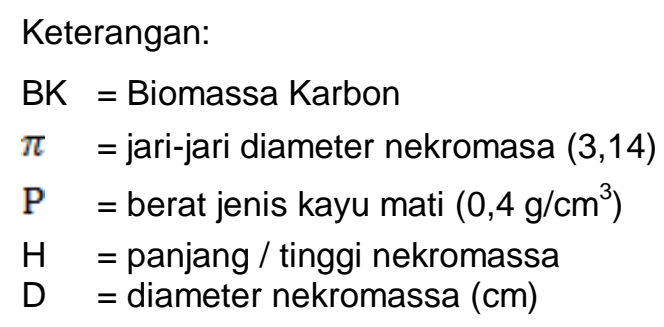

$$
\begin{gathered}
\text { Total biomassa pohon Btot }(\mathrm{kg})=\mathrm{BK}_{1}+\mathrm{BK}_{2}+\ldots \ldots+\mathrm{BK}_{\mathrm{n}} \\
\text { Biomassa per satuan luas (ton/ha) }=\frac{\mathrm{Btot}}{\mathrm{N}}
\end{gathered}
$$

Keterangan:

$\mathrm{BK}=$ Berat Karbon

Btot $=$ Total biomassa pohon $(\mathrm{kg})$

$\mathrm{N}=$ Luas area $\left(\mathrm{m}^{2}\right)$

Pengukuran biomassa tumbuhan bawah dan serasah pada plot ukur $0,5 \mathrm{~m} \times 0,5 \mathrm{~m}$ dengan berat $100 \mathrm{~g}-300 \mathrm{~g}$ atau seluruh sample pada plot jika memilikik berat kurang dari $100 \mathrm{~g}$ yang kemudian dilakukan pengovenan hinggan konstan. Metode pengukuran biomassa tumbuhan bawah dan serasah dilakukan dengan menggunakan metode Biomass Expansion Factor (BEF) (Brown 1997). 
Pendugaan karbon tersimpan selanjutnya menggunakan metode berdasarkan persamaan dari Intergovernmental Panel on Climate Change (IPCC) (2006), karbon tersimpan pada vegetasi hutan sebesar $47 \%$ sehingga rumus yang digunakan adalah:

Karbon tersimpan $=$ Biomassa total $\times 0,47$

\section{HASIL DAN PEMBAHASAN}

\section{A. Perbandingan jumlah biomassa pada pola tanam agroforestri sederhana dan agroforestri kompleks di KPH Batutegi}

Biomassa merupakan bahan organik tanaman pada tutupan lahan yang terdiri dari biomassa bagian atas permukaan tanah, baik tanaman hidup maupun mati. Biomassa didapatkan dari hasil proses fotosintesis tanaman baik tanaman alga, pohon, dan tumbuhan lainnya dengan bantuan sinar matahari (Azham, 2015; Papilo et al.. 2016). Semakin besar nilai biomassa suatu kawasan maka semakin tinggi nilai karbon tersimpan yang dimiliki, sehingga dapat memberikan peran yang semakin besar dalam meminimalisir efek pemanasan global (Tuah et al. 2017). Biomassa yang diperoleh berdasarkan hasil penelitian disajikan pada Tabel 1.

Tabel 1. Biomassa tanaman pada pola tanaman agroforestri sederhana dan agroforestri kompleks di KPH Batutegi

Tabel 1. Plant biomass on simple agroforestry and complex agroforestry crop patterns in KPH Batutegi

\begin{tabular}{|c|c|c|c|c|c|c|c|c|}
\hline \multirow{2}{*}{$\begin{array}{l}\text { Jenis Pola } \\
\text { Tanam }\end{array}$} & \multirow{2}{*}{ No. Plot } & \multicolumn{2}{|c|}{$\begin{array}{l}\text { Biomassa } \\
\text { Pohon Hidup } \\
\text { (ton/ ha) }\end{array}$} & \multicolumn{2}{|c|}{$\begin{array}{l}\text { Biomassa } \\
\text { Pohon Mati } \\
\text { (ton/ ha) }\end{array}$} & \multirow{2}{*}{$\begin{array}{c}\text { Biomassa } \\
\text { Tumbuhan } \\
\text { Bawah } \\
\text { (ton/ha) }\end{array}$} & \multirow{2}{*}{$\begin{array}{l}\text { Biomassa } \\
\text { Serasah } \\
\text { (ton/ha) }\end{array}$} & \multirow{2}{*}{ Total } \\
\hline & & $\begin{array}{l}\text { Poho } \\
\text { n } \\
\text { Besar }\end{array}$ & Pohon & $\begin{array}{l}\text { Poho } \\
\text { n } \\
\text { Besar }\end{array}$ & $\begin{array}{c}\text { Poho } \\
\text { n }\end{array}$ & & & \\
\hline \multirow{6}{*}{$\begin{array}{l}\text { Agroforestri } \\
\text { Kompleks }\end{array}$} & 1 & 74.87 & 194.28 & 0 & 19.84 & 1.32 & 4.24 & 294.54 \\
\hline & 2 & 55.89 & 265.23 & 0 & 2.29 & 0.92 & 2.16 & 326.50 \\
\hline & 3 & 49.33 & 35.76 & 0 & 0 & 0.4 & 2.72 & 88.21 \\
\hline & 4 & 191.74 & 17.84 & 0 & 0 & 1.68 & 3.32 & 214.58 \\
\hline & 5 & 0.07 & 236.15 & 303.31 & 0 & 0.4 & 6.52 & 546.45 \\
\hline & 6 & 12.53 & 138.74 & 0 & 3.51 & 1.28 & 2.64 & 158.69 \\
\hline Rata-rata & & 64.07 & 148 & 50.55 & 4.27 & 1 & 3.6 & \\
\hline \multirow{6}{*}{$\begin{array}{l}\text { Agroforestri } \\
\text { Sederhana }\end{array}$} & 1 & 23.66 & 65.02 & 77.11 & 0 & 2.04 & 2.12 & 169.95 \\
\hline & 2 & 43.18 & 54.21 & 21.35 & 6.76 & 0.8 & 2.08 & 128.39 \\
\hline & 3 & 17.87 & 38.82 & 24.99 & 11.77 & 1.16 & 2.44 & 97.06 \\
\hline & 4 & 25.14 & 45.25 & 0 & 32.35 & 3.08 & 3.88 & 109.70 \\
\hline & 5 & 66.31 & 46.14 & 0 & 0 & 0.56 & 5.28 & 118.29 \\
\hline & 6 & 100.42 & 28.61 & 0 & 0 & 0.44 & 5.04 & 134.51 \\
\hline Rata-rata & & 46.1 & 46.34 & 20.58 & 8.48 & 1.35 & 3.47 & \\
\hline
\end{tabular}

Sumber : Data primer (2020)

Biomassa tertinggi baik pada pola tanam agroforestri sederhana dan agroforestri kompleks terdapat pada biomassa pohon hidup. Biomassa rata-rata pada pohon dengan diameter >30 adalah $64.07 \mathrm{ton} /$ ha dan pohon dengan diameter 5-30 cm memiliki rata-rata biomassa sebesar 148 ton/ ha pada pola tanam agroforestri kompleks. 
Hasil analisis pada pola tanam agroforestri sederhana, menunjukan bahwa jumlah biomassa pohon hidup pada pohon dengan diameter $>30 \mathrm{~cm}$ adalah 46.1 ton/ha dan 46.34 ton/ha pada pohon dengan diameter $5-30 \mathrm{~cm}$. Selaras dengan hasil penelitian yang telah dilakukan oleh Aprianto et al. (2016) yang menyatakan bahwa pohon memiliki peran penting sebagai penyumbang biomassa terbesar. Dari data tersebut terlihat perbedaan bahwa biomassa pohon hidup pada pola tanam agroforestri kompleks lebih besar dari biomassa pohon hidup pada pola tanam agroforestri sederhana. Hal ini terjadi karena jumlah dan jenis pohon pada pola tanam agroforestri kompleks lebih banyak dibandingkan dengan pola tanam agroforestri sederhana sehingga biomassa yang diperoleh lebih besar pada agroforestri kompleks. Menurut Putri \& Wulandari (2015); Mandari et al. (2016); Baliton et al. (2017) jumlah dan jenis atau kerapatan pohon mempengaruhi nilai biomassa tanaman. Nilai Indeks Nilai Penting (INP) dan Summed Dominance Ratio (SDR) tanaman pada pola tanam agroforestri sederhana dan agroforestri kompleks disajikan pada Tabel 2

Tabel 2. Nilai INP dan SDR tanaman pada pola tanam agroforestri sederhana dan agroforestri kompleks Table 2. INP and SDR values of plants in simple and complex agroforestry cropping patterns

\begin{tabular}{|c|c|c|c|c|c|c|}
\hline \multirow[b]{2}{*}{ fase } & \multirow{2}{*}{$\begin{array}{l}\text { Pola } \\
\text { tanam }\end{array}$} & \multirow[b]{2}{*}{ No } & \multicolumn{2}{|r|}{ Jenis Tanaman } & \multirow[b]{2}{*}{ INP (\%) } & \multirow{2}{*}{$\begin{array}{l}\text { SDR } \\
(\%)\end{array}$} \\
\hline & & & $\begin{array}{l}\text { Nama } \\
\text { lokal }\end{array}$ & Nama IImiah & & \\
\hline \multirow[t]{21}{*}{ Pohon } & Agroforestri & 1 & Mahoni & Swietenia macrophylla & 34.82 & 11.61 \\
\hline & sederhana & 2 & Karet & Hevea brasiliensis & 23.00 & 7.67 \\
\hline & & 3 & Gaharu & Aquilaria malaccensis & 13.80 & 4.60 \\
\hline & & 4 & Durian & Durio zibethinus & 25.05 & 8.35 \\
\hline & & 5 & Alpukat & Persea americana & 12.69 & 4.23 \\
\hline & & 6 & Sonokeling & Dalbergia latifolia & 65.90 & 21.97 \\
\hline & & 7 & Cempaka & Magnolia champaca & 24.09 & 8.03 \\
\hline & & 8 & Jengkol & Archidendron pauciflorum & 31.86 & 10.62 \\
\hline & & 9 & Kemiri & Aleurites moluccanus & 37.20 & 12.40 \\
\hline & & 10 & Rambutan & Nephelium lappaceum & 31.60 & 10.53 \\
\hline & Total & & & & 300 & 100 \\
\hline & Agroforestri & 1 & Cempaka & Magnolia champaca & 31.10 & 10.37 \\
\hline & kompleks & 2 & Mahoni & Swietenia macrophylla & 71.33 & 23.78 \\
\hline & & 3 & Jengkol & Archidendron pauciflorum & 22.85 & 7.62 \\
\hline & & 4 & Sonokeling & Dalbergia latifolia & 35.71 & 11.90 \\
\hline & & 5 & Kemiri & Aleurites moluccanus & 26.81 & 8.94 \\
\hline & & 7 & Randu & Ceiba pentandra & 13.00 & 4.33 \\
\hline & & 8 & Durian & Durio zibethinus & 12.28 & 4.09 \\
\hline & & 9 & Dadap & Erythrina variegata & 46.47 & 15.49 \\
\hline & & 10 & Gaharu & Aquilaria malaccensis & 31.65 & 10.55 \\
\hline & Total & & & & 300 & \\
\hline
\end{tabular}


Pendugaan Stok Karbon Pada Pola Tanam Agroforestri... (Wulandari, dkk)

\begin{tabular}{|c|c|c|c|c|c|c|}
\hline \multirow[t]{13}{*}{ Tiang } & Agroforestri & 1 & Alpukat & Persea americana & 18.70 & 6.23 \\
\hline & \multirow[t]{12}{*}{ sederhana } & 2 & Sonokeling & Dalbergia latifolia & 21.26 & 7.09 \\
\hline & & 3 & Gaharu & Aquilaria malaccensis & 12.42 & 4.14 \\
\hline & & 4 & Karet & Hevea brasiliensis & 21.71 & 7.24 \\
\hline & & 5 & Mahoni & Swietenia macrophylla & 15.16 & 5.05 \\
\hline & & 6 & Jengkol & Archidendron pauciflorum & 32.54 & 10.85 \\
\hline & & 7 & Durian & Durio zibethinus & 25.22 & 8.41 \\
\hline & & 8 & Cempaka & Magnolia champaca & 19.78 & 6.59 \\
\hline & & 9 & Cengkeh & Syzygium aromaticum & 12.64 & 4.21 \\
\hline & & 10 & Gamal & Gliricidia sepium & 26.67 & 8.89 \\
\hline & & 11 & Kopi & Coffea robusta & 50.28 & 16.76 \\
\hline & & & Robusta & & & \\
\hline & & 12 & Petai & Parkia speciosa & 43.63 & 14.54 \\
\hline & \multicolumn{4}{|l|}{ Total } & 300 & 100 \\
\hline & Agroforestri & 1 & Cempaka & Magnolia champaca & 54.87 & 18.29 \\
\hline & \multirow[t]{9}{*}{ kompleks } & 2 & Jengkol & Archidendron pauciflorum & 38.52 & 12.84 \\
\hline & & 3 & Salam & Syzygium polyanthum & 18.55 & 6.18 \\
\hline & & 4 & Dadap & Erythrina variegata & 11.68 & 3.89 \\
\hline & & 5 & Kopi & Coffea robusta & 69.22 & 23.07 \\
\hline & & & Robusta & & & \\
\hline & & 6 & Mahoni & Swietenia macrophylla & 17.05 & 5.68 \\
\hline & & 7 & Pinang & Areca catechu & 30.27 & 10.09 \\
\hline & & 8 & Gamal & Gliricidia sepium & 39.42 & 13.14 \\
\hline & & 9 & Durian & Durio zibethinus & 20.41 & 6.80 \\
\hline & Total & & & & 300 & 100 \\
\hline \multirow[t]{9}{*}{ Pancang } & Agroforestri & 1 & Gamal & Gliricidia sepium & 88.71 & 29.57 \\
\hline & \multirow[t]{3}{*}{ sederhana } & 2 & Jengkol & Archidendron pauciflorum & 41.17 & 13.72 \\
\hline & & 3 & Kopi & Coffea robusta & 170.11 & 56.70 \\
\hline & & & Robusta & & & \\
\hline & Total & & & & 300 & 100 \\
\hline & Agroforestri & 1 & Kopi & Coffea robusta & 213.98 & 71.33 \\
\hline & kompleks & & Robusta & & & \\
\hline & & 2 & Cempaka & Magnolia champaca & 86.02 & 28.67 \\
\hline & Total & & & & 300 & 100 \\
\hline
\end{tabular}


Tabel 2 menunjukan bahwa jumlah tanaman pada pola tanam agroforestri kompleks lebih tinggi dibandingkan dengan pola tanam agroforestri kompleks yang terlihat pada nilai INP dan SDR. Nilai INP menentukan struktur dan pola penyebaran tanaman yang ada pada setiap pola tanam (Petmasi et al. 2016). Jenis tanaman yang memiliki nilai INP tertinggi ada pada pola tanam agroforestri kompleks dengan jenis tanaman mahoni (Swietenia macrophylla) yaitu $71,33 \%$ dan $23.78 \%$. Nilai INP tertinggi fase tiang terdapat pada jenis tanaman kopi robusta (Coffea robusta) di pola tanam agroforestri kompleks dengan nilai $69.22 \%$ dan nilai SDR sebesar $23.07 \%$. Tingginya nilai INP menunjukan tingkat peranan penting jenis tanaman tersebut dalam komunitas (Kamaruddin et al. 2016). Selain itu INP juga digunakan untuk melihat dominasi, kerapatan, dan frekuensi jenis tanaman dala komunitas tertentu (Pamoengkas \& Zamzam 2017). Nilai SDR dapat menunjukan jenis spesies yang paling melimpah pada suatu komunitas (Natalia et al. 2014). Oleh sebab itu nilai INP dan SDR mempengaruhi besaran nilai biomassa tanaman.

Biomassa pada tumbuhan bawah dan serasah pada pola tanam agroforestri kompleks juga memiliki nilai yang lebih besar dibandingkan dengan biomassa tumbuhan bawah dan serah pada pola tanam agroforestri sederhana. Hal ini terjadi karena kerapatan pada pola tanam agroforestri kompleks lebih tinggi dibandingkan dengan kerapatan pohon pada pola tanam agroforestri sederhana. Biomassa tumbuhan bawah akan semakin kecil apabila kerapatan pohon semakin tinggi, karena cahaya matahari yang membantu dalam pertumbuhan tanaman akan semakin berkurang karena adanya persaingan dalam memperoleh cahaya matahari (Azham, 2015; Wiarta et al. 2017; Nofrianto et al. 2018; Hanafi et al. 2018; Rajaguguk et al. 2018). Kerapatan tajuk pohon juga mempengaruhi jumlah serasah yang jatuh ke lantai hutan akibat dari persaingan dalam memperoleh sinar matahari (Budiman et al. 2015; Erly et al. 2019 ). Selain itu, umur tegakan juga mempengaruhi banyaknya serasah (Azham, 2015; Danial et al. 2019). Besaran nilai biomassa pada tiap komponen menunjukan besaran peran proses fotosintesis tanaman. Karbon di atmosfer akan diikat dan disimpan oleh tanaman melalu proses fotosintesis yang kemudian ditunjukan dalam bentuk besaran biomassa tanaman (Haryati et al. 2014; Suryono et al. 2018).

\section{B. Perbandingan stok karbon pada pola tanam agroforestri sederhana kompleks di KPH Batutegi}

Nilai karbon tersimpan diperoleh dari akumulasi karbon tersimpan tegakan dan tumbuhan serta serasah. Hasil perhitungan simpanan karbon pada pola tanam agroforestri sederhana dan agroforestri kompleks di KPH Batutegi dapat dilihat pada Tabel 3.

Tabel 3. Karbon tersimpan masing-masing plot pada pola tanam agroforestri kompleks dan agroforestri sederhana di KPH Batutegi

Table 3. Stored carbon for each plot in the complex and simple agroforestry cropping patterns in the KPH Batutegi

\begin{tabular}{|c|c|c|c|c|c|c|c|c|}
\hline \multirow{2}{*}{$\begin{array}{l}\text { Pola } \\
\text { Tanam }\end{array}$} & \multirow{2}{*}{$\begin{array}{l}\text { No. } \\
\text { Plot }\end{array}$} & \multicolumn{2}{|c|}{$\begin{array}{l}\text { pohon hidup } \\
\text { (ton/ha) }\end{array}$} & \multicolumn{2}{|c|}{$\begin{array}{l}\text { pohon mati } \\
\text { (ton/ha) }\end{array}$} & \multirow{2}{*}{$\begin{array}{c}\text { tumbuhan } \\
\text { bawah } \\
\text { (ton/ha) }\end{array}$} & \multirow{2}{*}{ serasah } & \multirow{2}{*}{ total } \\
\hline & & $\begin{array}{l}\text { pohon } \\
\text { besar }\end{array}$ & pohon & $\begin{array}{l}\text { pohon } \\
\text { besar }\end{array}$ & pohon & & & \\
\hline \multirow[t]{4}{*}{$\begin{array}{l}\text { Agroforestri } \\
\text { Kompleks }\end{array}$} & 1 & 35.19 & 91.31 & 0 & 9.32 & 0.62 & 1.99 & 138.43 \\
\hline & 2 & 26.27 & 124.66 & 0 & 1.08 & 0.43 & 1.02 & 153.45 \\
\hline & 3 & 23.18 & 16.81 & 0 & 0 & 0.19 & 1.28 & 41.46 \\
\hline & 4 & 90.12 & 8.39 & 0 & 0 & 0.79 & 1.56 & 100.85 \\
\hline
\end{tabular}


Pendugaan Stok Karbon Pada Pola Tanam Agroforestri... (Wulandari, dkk)

\begin{tabular}{lrrrrrrrr} 
& 5 & 0.03 & 110.99 & 142.56 & 0 & 0.19 & 3.06 & 256.83 \\
& 6 & 5.89 & 65.21 & 0 & 1.65 & 0.60 & 1.24 & 74.58 \\
\hline rata-rata & & 30.11 & 69.56 & 23.76 & 2.01 & 0.47 & 1.69 & \\
\hline Agroforestri & & & & & & & & \\
Sederhana & 1 & 11.12 & 30.56 & 36.24 & 0 & 0.96 & 1.00 & 79.88 \\
& 2 & 20.29 & 25.48 & 10.04 & 3.18 & 0.38 & 0.98 & 60.34 \\
& 3 & 8.40 & 18.25 & 11.75 & 5.53 & 0.55 & 1.15 & 45.62 \\
& 4 & 11.82 & 21.27 & 0 & 15.20 & 1.45 & 1.82 & 51.56 \\
& 5 & 31.16 & 21.69 & 0 & 0 & 0.26 & 2.48 & 55.60 \\
& 6 & 47.20 & 13.45 & 0 & 0 & 0.21 & 2.37 & 63.22 \\
\hline rata-rata & & 21.67 & 21.78 & 9.67 & 3.99 & 0.63 & 1.63 & \\
\hline
\end{tabular}

Sumber : Data Primer (2020)

Berdasarkan Tabel diatas terlihat bahwa nilai karbon tersimpan pohon hidup, tumbuhan bawah, dan serasah pada pola tanama agroforestri kompleks lebih besar dibandingkan pada pola tanam agroforestri sederhana. Nilai karbon tersimpan pada pola tanam agroforestri kompleks dan agroforestri sedehana untuk fase pohon hidup memiliki perbedaan yang signifikan. Fase pohon hidup pada pola tanam agroforestri kompleks sebesar 99.67 ton/ha, sedangkan pada pola tanam agroforestri sederhana sebesar 43.45 ton/ ha. Hal tersebut disebabkan oleh perbedaan jumlah dan jenis pohon pada tiap pola tanam, baik yang ditanam secara sengaja oleh petani atau secara alami. Hal ini sejalan dengan pengertian agroforestri kompleks yang dikemukan oleh Hutagaol (2020), yang menyatakan bahwa agroforestri kompleks memiliki banyak jumlah dan jenis pohon sehingga fisik dan dinamikanya menyerupai hutan alam. Jumlah dan jenis pohon akan mempengaruhi besaran biomassa tanaman sehingga secara otomatis juga akan mempengaruhi jumlah karbon tersimpan pada suatu lahan (Insusanty et al. 2017; Danial, 2019). Selain itu diameter dan tinggi pohon juga memiliki pengaruh terhadap besaran biomassa karbon (Insusanty et al. 2017).

Potensi karbon tersimpan pada fase pohon memiliki nilai yang lebih tinggi dibandingkan dengan potensi karbon tersimpan pada fase serasah dan tumbuhan bawah. Hal ini dipengaruhi oleh intensitas sinar matahari pada tumbuhan bawah dan serasah sangat terbatas karena terhalang oleh tajuk tumbuhan atas (Pambudi et al. 2017). Nilai karbon tersimpan pada fase pohon hidup terbesar ada pada plot ukur 2 pada pola tanam agroforestri kompleks dengan total 150.93 ton/ha. Ketika dianalisis di plot yang sama, nilai karbon tersimpan pada serasah sebesar 1.02 ton/ha dan karbon tersimpan pada tumbuhan bawah sebesar 0.43 ton/ha. Namun berdasarkan Tabel 3, karbon tersimpan pada tumbuhan serasah akan lebih besar dibandingkan dengan karbon tumbuhan bawah. Tumbuhan bawah tetap memiliki peran terhadap penyerapan karbon meskipun lebih rendah dibandingkan tanaman serasah (Yunita 2016).

Kondisi tersebut sejalan dengan hasil penelitian yang dilakukan di Kabupaten Kampar oleh Tuah et al. (2017), bahwa simpanan karbon serasah lebih besar dibandingkan dengan nilai simpan karbon tumbuhan bawah akibat pengaruh vegetasi yang menggugurkan daunnya, kualitas tempat tumbuh dan intensitas sinar matahari. Hal ini juga mempengaruhi besaran karbon serasah pada pola tanam agroforestri kompleks yang relatif lebih tinggi yaitu 10.15 ton/ha dibandingkan karbon serasah pada pola tanam agroforestri sederhana yaitu sebesar 9.79 ton/ha. Bahan organik serasah yang lebih tinggi dibandingkan tumbuhan bawah juga mempengaruhi besaran karbon, hal ini terjadi karena serasah merupakan kumpulan dari ranting, guguran daun hidup, lumut, bagian kulit kayu, serta bagian dari bunga dan buah 
(Insusanty et al. 2017). Secara lengkap karbon tersimpan fase pohon hidup, pohon mati, serasah, dan tumbuhan bawah disajikan pada Tabel 4.

Tabel 4. Total karbon pada pola tanam agroforestri sederhana dan agroforestri kompleks di KPH Batutegi.

Table 4. Total carbon in simple agroforestry and complex agroforestry cropping patterns in KPH Batutegi.

\begin{tabular}{|c|c|c|c|c|c|c|c|c|}
\hline \multirow{2}{*}{$\begin{array}{l}\text { Pola } \\
\text { Tanam }\end{array}$} & \multicolumn{2}{|c|}{$\begin{array}{l}\text { Pohon Hidup } \\
\text { (ton/ ha) }\end{array}$} & \multicolumn{2}{|c|}{$\begin{array}{l}\text { Pohon Mati } \\
\text { (ton/ ha) }\end{array}$} & \multirow{2}{*}{$\begin{array}{c}\text { Tumbuhan } \\
\text { - Bawah } \\
\text { (ton/h) }\end{array}$} & \multirow{2}{*}{$\begin{array}{l}\text { Serasah } \\
\text { (ton/ha) }\end{array}$} & \multirow{2}{*}{ Total } & \multirow{2}{*}{$\begin{array}{l}\text { Rata- } \\
\text { Rata }\end{array}$} \\
\hline & $\begin{array}{l}\text { Pohon } \\
\text { Besar }\end{array}$ & Pohon & $\begin{array}{l}\text { Pohon } \\
\text { Besar }\end{array}$ & Pohon & & & & \\
\hline $\begin{array}{l}\text { Agroforestri } \\
\text { Kompleks } \\
\text { Agroforestri }\end{array}$ & 180.68 & 417.36 & 142.56 & 12.05 & 2.82 & 10.15 & 765.61 & 127.60 \\
\hline sederhana & 129.99 & 130.68 & 58.02 & 23.91 & 3.80 & 9.79 & 356.21 & 59.37 \\
\hline
\end{tabular}

Sumber : Data Primer (2020)

Karbon tersimpan sebesar 138 ton/ha atau lebih masuk kedalam kategori baik, dan begitupula sebaliknya (Intergovermental Panel on Climate Change 2006). Sehingga stok karbon pada pola tanam agroforestrti sederhana dan kompleks di KPH Batutegi masuk kedalam kategori baik. Namun total stok karbon pada pola tanam agroforestri kompleks dua kali lebih tinggi dibandingkan pada pola tanam agroforestri sederhana yaitu 765.61 ton/ha dan 356.21 ton/ha. Hasil tersebut menunjukan bahwa pola tanam agroforestri kompleks lebih baik dan lebih optimal dalam menyerap karbon. Berdasarkan kondisi tersebut maka dapat dikatakan bahwa agroforestri kompleks dapat berkontribusi lebih besar untuk meminimalisir efek pemanasan global melalui proses penyerapan karbon. Grafik perbandingan potensi penyerapan karbon pada pola tanam agroforestri sederhana dan agroforestri kompleks disajikan pada gambar 2 berikut.

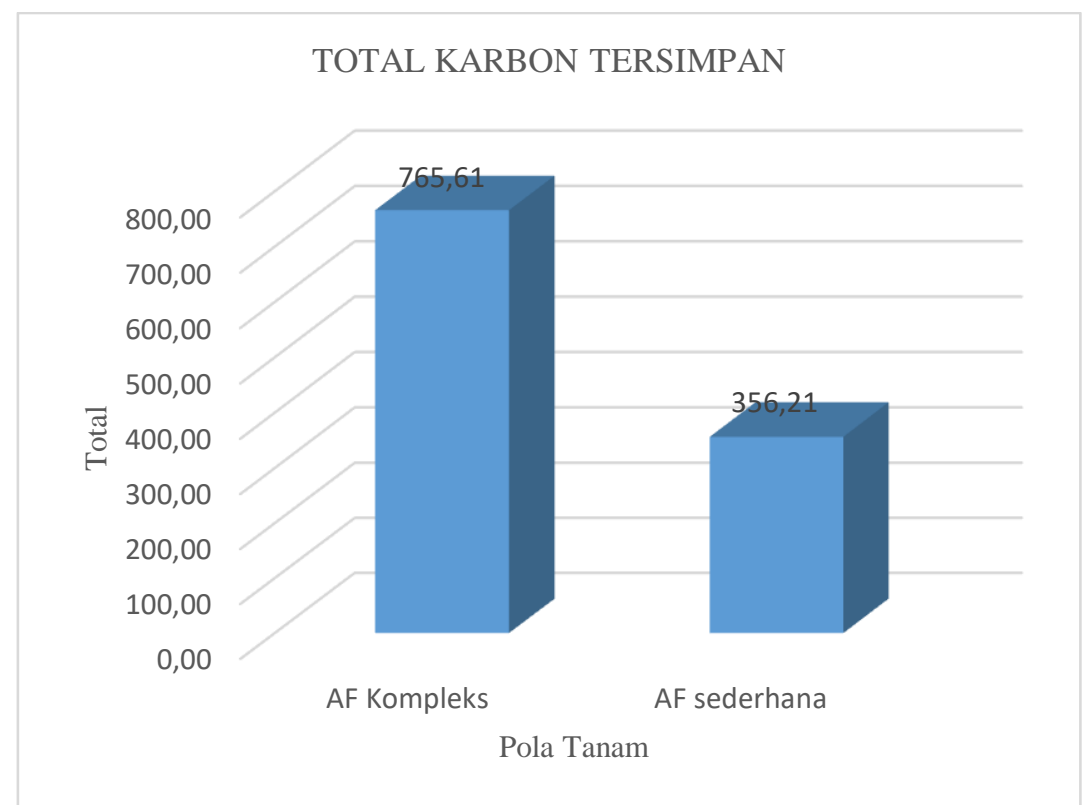

Gambar 2 Grafik total karbon tersimpan pada pola tanam agroforestri sederhana dan kompleks Figure 2 Graph of total carbon stock in simple and complex agroforestry cropping patterns

\section{KESIMPULAN}

[122] This work is licensed under a Creative Commons Attribution 4.0 International License 
Potensi Karbon stok pola tanam agroforestri kompleks dua kali lebih besar dibandingkan pada pola tanam agroforestri sederhana. Nilai karbon tersimpan pada pola tanam agroforestri kompleks adalah 765.61 ton/ha, sedangkan pada pola tanam agroforestri sederhana memiliki nilai karbon tersimpan sebesar 356.21 ton/ha. jumlah karbon yang tersimpan pada pola tanam agroforestri kompleks dan agroforestri sederhana pada wilayah kelola KPH Batutegi menunjukan bahwa (secara total) dapat masuk kedalam kategori baik berdasarkan rekomendasi dari IPCC.

\section{DAFTAR PUSTAKA}

Adinugroho, W.C., Indrawan, A., Suptiyanto., Arifin, H.D. 2013. Kontribusi sistem agroforestri terhadap cadangan karbon di hulu DAS kali bekasi. Jurnal Hutan Tropis, 1(3), 242-249.

Alfatikha, M., Herwanti, S., Febryano, I.G., Yuwono, S.B. 2020. Identifikasi jenis tanaman agroforestri untuk mendukung ketahanan pangan rumah tangga di Desa Pulau Pahawang. Journal of Forestry Research, 3(2), 55-63.

Aprianto, D. 2015. Karbon tersimpan pada kawasan sistem agroforestry di register 39 datar setuju KPHL Batutegi Kabupaten Tanggamus . Skripsi: Universitas Lampung. Bandar Lampung.

Aprianto, D., Wulandari, C. dan Masruri, N.W. 2016. Karbon tersimpan pada kawasan sistem agroforestry di register 39 datar setuju KPHL Batutegi Kabupaten Tanggamus. J. Sylva Lestari, 4(1), 21-30.

Arifin, S. 2015. Peranan dan fungsi hukum lingkungan mengantisipasi dampak perubahan iklim pada sumberdaya pesisir Sumatera Utara. Jurnal hukum samudra keadilan, 10(2), 168176.

Azham, Z. 2015. Estimasi Cadangan Karbon Pada Tutupan Lahan Hutan Sekunder, Semak Dan Belukar Di Kota Samarinda. Jurnal AGRIFOR, 18(2), 325-338.

Baliton, R.S., Wulandari, C., Landicho, L.D., Cabahug, R.E.D., Paelmo, R.F., Comia, R.A., Visco, R.G., Buidono, P. Herwanti, S., Rusita., Catillo, A.K.S. 2017. Ecological Services of Agroforestry Landscapes in Selected Watershed Areas in the Philippines and Indonesia. Biotropia, 24(1), 71-84.

Bhaskara, D.R. 2017. Karbon Tersimpan pada Repong Damar Pekon Pahmungan Kecamatan Pesisir Tengah Kabupaten Pesisir Barat. Skripsi: Universitas Lampung. Lampung.

Brown, S. 1997. Estimating Biomass anda Biomass Change of Tropical Forest, a Primer. FAO Forestry Paper 134. Buku, FAO Rome, 55 halaman.

Budiman, M., Hardiansyah, G., Darwati, H. 2015. Estimasi Biomassa Karbon Serasah Dan Tanahpada Basal Area Tegakan Meranti Merah(Shorea Macrophylla) Di Areal Arboretumuniversitas Tanjungpura Pontianak. Jurnal Hutan Lestari, 3(1), 98-107.

Danial., Ilham, W., Asyari, M. 2019. Pendugaan Karbon Tersimpan Pada Permukaan Tanah Di Berbagai Jalur Hijau Kecamatan Banjarbaru Utara Kota Banjarbaru, 2(4), 667-674.

Dede, M., Pramulatsih, G. P., Widiawaty, M. A., Ramadhan, Y. R., Ati, A. 2019. Dinamika suhu permukaan dan kerapatan vegetasi di kota cirebon. Jurnal Meteoroligi Klimatologi dan Geofisika, 6(1), 23-30. 
Erly, H., Wulandari, C., Safe'i, R., Kaskoyo, H., Winarno, G. D. 2019. Keanekaragaman Jenis dan Simpanan Karbon Pohon di Resort Pemerihan, Taman Nasional Bukit Barisan Selatan. Jurnal Sylva Lestari, 7(2), 139-149.

Fitri, A., Ulfa, A. 2015. Perencanaan Penerapan Konsep Zero Run-Off dan Agroforestri Berdasarkan Kajian Debit Sungai di Sub DAS Belik, Sleman, Daerah Istimewa Yogyakarta. Jurnal Perencanaan Wilayah dan Kota, 26(3).

Hairiah, K. dan Rahayu, S. 2007. Pengukuran Karbon Tersimpan di Berbagai Macam Penggunaan Lahan. Buku. World Agroforestri Center-ICRAF. Bogor. 77 halaman.

Hairiah, K., Ekadinata, A., Sari, R. R., Rahayu, S. 2011. Pengukuran cadangan karbon di berbagai macam penggunaan lahan. Buku: World agroforestry center-icrf. Bogor.

Hanafi, N., Afitah, I., Jariah. 2018. Cadangan Karbon pada "Kabun" di Kabupaten Katingan Kalimantan Tengah. Jurnal IImiah Pertanian dan Kehutanan, 5(2), 97-104.

Haryati, T., Mahyudin, I., Fithrian, A., Haris, A. 2014. Pendugaan potensi kebun karet rakyat sebagai cadangan karbon di kecamtan cempaka kota banjarbaru provinsi kalimantan selatan. Jurnal IImiah Bidang Pengelolaan Sumberdaya Alam dan Ligkungan, 10(3), 150156.

Hutagaol, R. R. 2020. Potensi Tumbuhan Lokal Di Areal Tembawang Desa Suka Jaya Kabupaten Sintang. Publikasi Informasi Pertanian, 16(30), 61-76.

Indriyanto. 2006. Ekologi Hutan. Buku: PT. Bumi Aksara. Jakarta.

Insusanty, E., Ikhwan, M., Sadjati, E. 2017. Kontribusi Agroforestri Dalam Mitigasi Gas Rumah Kaca Melalui Penyerapan Karbon. Jurnal Hutan Tropis, 5(3), 181-187.

IPCC (Intergovernmental Panel on Climate Change). 2007. Contribution of Working Group III to The Fourth Assessment Report of the Intergovernmental Panel on Climate Change.

Buku. Cambridge University Press. 863 halaman.

Kamaruddin, Z.K., Rondonuwo, S. B., Maabuatm, P. V. 2016. Keragaman Lamun (Seagrass) di Pesisir Desa Lihunu Pulau Bangka Kecamatan Likupang Kabupaten Minahasa Utara, Sulawesi Utara. Junral MIPA Unsrat Online, 5(1), 20-24.

Mandari, D. Z., Gunawan, H., Isda, M. N. 2016. Penaksiran Biomassa dan Karbon Tersimpan pada Ekosistem Hutan Mangrove di Kawasan Bandar Bakau Dumai. Jurnal Riau Biologia, 1(3), 17-23.

Natalia, D., Yuwono, S. B., Qurniati, R. 2014. Potensi Penyerapan Karbon Pada Sistem Agroforestri Di Desa Pesawaran Indah Kecamatan Padang Cermin Kabupaten Pesawaran Provinsi Lampung. Jurnal Sylva Lestari, 2(1), 11-20.

Nofrianto., Ratnaningsih, A. T., Ikhwan, M. 2018. Pendugaan Potensi Karbon Tumbuhan Bawah Dan Serasah Di Arboretum Universitas Lancang Kuning. Jurnal Kehutanan, 13(2), 144155.

Novasari, D. 2019. Sistem pengelolaan hutan dan perubahan tutupan lahan pada lahan hutan kemasyarakatan di kesatuan pengelolaan hutan batutegi. Universitas Lampung. DOI: 10.1017/CBO9781107415324.004

Novasari, D., Qurniati, R., Duryat. 2020. Keragaman jenis tanaman pada sistem pengelolaan hutan kemasyrakatan. jurnal belantara, 3(1), 41-47. 
Pambudi, P. A., Rahardjanto, A., Nurwidodo., Husamah. 2017. Analisis Serapan Karbondioksida (Co2) Tumbuhan Di Blok Puyer Kawasan Ranu Pani Taman Nasional Bromo Tengger Semeru (Tnbts) Pada Tahun 2016. Prosiding Seminar Nasional III, 277282.

Pamoengkas, P., Zamzam, A. K. 2017. Komposisi Functional Species Group Pada Sistem Silvikultur Tebang Pilih Tanam Jalur di Area iUPHHK-HA Pt. Sarpatim, Kalimantan Tengah. Jurnal Silvikultur Tropika, 8(3), 160-169.

Papilo, P., Kunaifi., Erliza, H., Nurmiati., Pari, R.F. 2016. Penilaian Potensi Biomassa Sebagai Alternatif Energi Kelistrikan. Jurnal PASTI, 9(2), 164-176.

Partiwi, A. 2019. Pengenalan pemicu pemanasan global menggunakan teknologi augmented reality berbasis desktop. Jurnal Ilmiah Teknologi dan Rekayasa, 24(100), 49-61.

Prihatmaji, Y.P., Fauzy, A., Rais, S. Firdaus, F. 2016. Analisis carbon footprint gedung perpustakaan pusat, rektorat, dan lab. MIPA UII berbasis vegetasi eksisting sebagai pereduksi emisi gas rumah kaca. Asian Journal of Innovation dan Entrepreneurship, 1(2), 148-155.

Putri, A. H. M., Wulandari, C. 2015. Potensi Penyerapan Karbon Pada Tegakan Damar Mata Kucing (Shorea Javanica) Di Pekon Gunung Kemala Krui Lampung Barat. Jurnal Sylva Lestari, 3(2), 13-20.

Rajaguguk, C. P., Febryano, I.G., Herwanti, S. 2018. Perubahan Komposisi Jenis Tanaman dan Pola Tanam pada Pengelolaan Agroforestri Damar. Jurnal Sylva Lestari, 6(3), 18-27.

Riswakhyuningsih, T. 2015. Pengembangan Suplemen Bahan Ajar Pemanasan Global Berwawasan Konservasi. Tesis: Universitas Negeri Semarang. Semarang.

Rizki, G. M., Bintoro, A., Hilmanto, R. 2016. Perbandingan emisi karbon dengan karbon tersimpan di hutan rakyat Desa Buana Sakti Kecamatan Batanghari Kabupaten Lampung Timur. Jurnal Sylva Lestari, 4(1), 89-96.

Salampessy, M. L., Febryano, I.G., Bone, I. 2017. Pengetahuan ekologi masyarakat lokal dalam pemilihan pohon pelindung padasistem agroforestri tradisional "Dusung" Pala di Ambon. Jurnal Penelitian Sosial dan Ekonomi Kehutanan, 14(2), 135-142.

Stevanus, C.T., Sahuri. 2014. Potensi peningkatan penyerapan karbon di perkebunan karet Sembawa, Sumatra Selatan. Widyariset, 17(3), 363-371.

Sukmawati, W., Arkeman, Y., Maarif, S. 2014. Inovasi sistem agroforestry dalam meningkatkan produktivitas kardkkam. Jurnal Teknik Industri, 4(1),58-64. doi: 10.25105/jti.v4i1.1563.

Sumilia., Akhir, N. Syarif, Z. 2019. Plant diversity in various agroforestry system based on cocoa in Pasaman, West Sumatra. International Journal of Environment, Agriculture and Biotechnology (IJEAB), 4(2), 402-406. doi: 10.22161/ijeab/4.2.22.

Suryono., Soenardjo, N., Wibowo, E., Ario, R., Rozy, E. F. 2018. Estimasi Kandungan Biomassa dan Karbon di Hutan Mangrove Perancak Kabupaten Jembrana, Provinsi Bali. Buletin Oseanografi Marina, 7(1), 1-8.

Tuah, N., Sulaeman, R., Yoza, D. 2017. Penghitungan Biomassa Dan Karbon Di Atas Permukaan Tanah Di Hutan Larangan Adat Rumbio Kab Kampar. Jurnal Online Mahasiswa Fakultas Pertanian Universitas Riau, 4(1), 1-10.

Wiarta, R., Astiani, D., Indrayani, Y., Muliah, F. 2017. Pendugaan Jumlah Karbon Tersimpan Pada Tegakan Jenis Bakau (Rhizophora Apiculata BI) Di luphhk Pt. Bina Ovivipari Semesta Kabupaten Kubu Raya. Jurnal Hutan Lestari, 5(2), 356-364. 
Wulandari, C., Landicho, L.D., Cabahug, R.E.D. Baliton, R.S., Banuwa, R.S., Herwanti, S., Biono, P. 2019. Food Security Status Agroforestry Landscapes of Way Betung Watershed, Indonesia and Molawin Dampalit Subwatershed, Philippines. Jurnal Manajemen Hutan Tropika, 25(3), 164-172.

Yudha, F. K. 2019. Potensi Pengurangan Emisi Gas Rumah Kaca dari Biogas Skala Rumah Tangga Tipe Floating Drum. Skripsi. Universitas Lampung. Lampung.

Yunita, L. 2016. Pendugaan Cadangan Karbon Tegakan Meranti (Shorea leprosula) Di Hutan Alam Pada Area Silin Pt Inhutani li Pulau Laut Kalimantan Selatan. Jurnal Hutan Tropis, 4(2), 187-197. 